programs, including the necessary components for shelter activation, operation (including provision of care), and demobilization of shelter sites.

Sheltering of medically fragile clients also may be necessary in areas of the world that are not subject to hurricanes, but may face other hazards (floods, tornados, civil unrest, hazardous materials incidents, etc.).

Keywords: Florida; hurricane; issues; lessons; medically fragile; shelter; systems

Prehosp Disast Med 2005:20(2):s75-s76

\section{After Sphere: An Evaluation to Determine Post- Emergency Phase Refugee Health Indicators}

\section{G. Greenough; E. Wall; R. Nazerali}

Center for International Emergency, Disaster, and Refugee Studies (CIEDRS), Johns Hopkins Bloomberg School of Public Health, Baltimore, Maryland USA

Objectives: In 1997, a collaboration of non-governmental organizations (NGOs) and the International Society of the Red Cross and Red Crescent launched the Sphere Project, which provided mostly qualitative health standards to aid agencies for humanitarian assistance in emergency refugee settings. Yet, despite such efforts, more than half of the world's refugees live in protracted living conditions for which there are no long-term, refugee health indicators.

Methods: Through triangulating data from $35 \mathrm{key}$ informant interviews and two focus group discussions, health indicators, appropriate for a post-emergency, refugee setting, were ascertained from the Kakuma Refugee Camp in Kakuma, Kenya. Participants included: (1) representatives from all nine ethnic refugee groups and vulnerable groups, including women, youth, and the disabled; (2) health sector administrators and providers, including community outreach, inpatient and outpatient personnel; and (3) administrative and operational personnel from other camp sectors directly impacting health services, including referral services, food, water and sanitation, and shelter.

Conclusions: Evaluation of the data determined that continuous quality improvement (CQI) at all levels of refugee health programming should be integrated in the post-emergency phase. This includes the supervision of refugee healthcare providers, community health workers, and health educators. Continuous quality improvement should include measuring the effectiveness of health programs within the healthcare facilities and community. This improvement must include a focus on human resource developmentperiodic continuing medical education, ensuring equitable benefits for local and refugee staff, and quality feedbackthat would improve care and strengthen morale. Refugees should be involved in the decision-making process and gradually take on greater roles in healthcare delivery.

Surveillance and curative services for chronic diseases, such as hypertension and diabetes, mental health issues, nutritional deficiencies, palliative care for human immunodeficiency virus (HIV) patients, and those with a terminal illness, should evolve in the post-emergency phase after infectious disease surveillance is established, and referral processes, especially for emergencies, should be streamlined.
Mechanisms to ensure horizontal coordination among agencies of various sectors should be in place. Linked data systems-e.g., household-based, post-food distribution monitoring linked with nutritional status of youngest children, sanitation and water data, shared with diarrhea incidence data-are points for coordination. Ensuring equal access to livelihoods and all levels of health care will minimize resentment between the local population and refugees.

Educational programs should become more focused as health problems emerge. Examples include nutritional counseling for HIV-positive mothers who don't breastfeed, family planning, and occupational and societal integration of the disabled. As this study illustrates, the post-emergency phase of the refugee environment has consensus-driven qualitative indicators that can be validated, standardized, and implemented to improve health care.

Keywords: effectiveness; evaluation; healthcare; indicators; postemergency; public health; refugees

Prebosp Disast Med 2005;20(2):s76

\section{Efficiency Analysis of the System of Health Support in the Refugee Camps in Northern Caucasus during Anti-terrorist Operations \\ V. Preobrazhenskiy}

All-Russian Centre for Disaster Medicine, Russia

From 1999 to 2003, the All-Russian Centre for Disaster Medicine (ARCDM), "Zaschita" of the Russian Ministry of Health provided health support of temporarily displaced persons, in accordance with the tasks assigned by the government. The main tasks for health provision were: (1) rendering emergency medical assistance for patients with acute diseases and traumatic injuries; (2) prevention and early detection of infectious diseases, including tuberculosis (TB); (3) medical examination and detection of people who needed in-patient treatment and specialized medical care; (4) vaccinations for children; (5) providing outpatient and polyclinical assistance; and (6) medical check-ups for patients with chronic diseases.

To achieve these tasks during the given period, multipurpose, field hospitals were deployed (therapeutic, TB, pediatric), in which various skilled and main types of specialized care were provided. Patients with chronic diseases and long treatment terms were sent to the medical institutions of the Republics of Ingushetia, Dagestan, and Kabardino-Balkaria. For highly technological types of medical assistance, the injured were sent to central, specialized, medical institutions (Moscow, St. Petersburg), as well as to regional specialized institutes (Vladikavkaz, Nalchik, etc.).

For early detection of somatic, psychological, and infectious diseases, a check-up team of physicians from the multipurpose field hospital went to the camps each day. The team included a physician-therapist, an infectionist, and a doctor specialized in functional diagnostics to review electrocardiograms (ECGs) and ultrasound studies. A special team detected patients and carried out prevention work with TB contact persons using house-to-house visits and fluorography. In some camps, outpatient, polyclinical assistance was provided with the help of doctors from humanitarian orga- 